\title{
Total synthesis of the proposed structure of astakolactin
}

\author{
Takayuki Tonoi ${ }^{*}$ Keisuke Mameda, Moe Fujishiro, Yutaka Yoshinaga and Isamu Shiina*
}

\author{
Full Research Paper \\ Address: \\ Department of Applied Chemistry, Tokyo University of Science,1-3 \\ Kagurazaka, Shinjuku-ku, Tokyo 162-8601, Japan \\ Email: \\ Takayuki Tonoi* - tonoi@rs.tus.ac.jp; Isamu Shiina* - \\ shiina@rs.kagu.tus.ac.jp \\ ${ }^{*}$ Corresponding author \\ Keywords: \\ aldol reaction; astakolactin; lactonization; MNBA; terpenoids
}

Open Access

\author{
Beilstein J. Org. Chem. 2014, 10, 2421-2427. \\ doi:10.3762/bjoc. 10.252 \\ Received: 29 June 2014 \\ Accepted: 01 October 2014 \\ Published: 17 October 2014 \\ Associate Editor: D. Dixon \\ (C) 2014 Tonoi et al; licensee Beilstein-Institut. \\ License and terms: see end of document.
}

\begin{abstract}
The first total synthesis of the proposed structure of astakolactin, a sesterterpene metabolite isolated from the marine sponge Cacospongia scalaris, has been achieved, mainly featuring Johnson-Claisen rearrangement, asymmetric Mukaiyama aldol reaction and MNBA-mediated lactonization.
\end{abstract}

\section{Introduction}

Astakolactin (1) is a novel sesterterpene metabolite [1-5] first reported in 2003 by Roussis et al [6]. It was isolated from the marine sponge Cacospongia scalaris, which was collected from the gulf of Astakos in the Ionian Sea near Greece. The structure proposed for compound $\mathbf{1}$ is a bicyclic linear sesterterpenoid bearing a furan unit and an eight-membered lactone tethered by a non-conjugated triene chain (Figure 1). Although the proposed structure of compound $\mathbf{1}$ is unusual, given that a number of compounds isolated from sponges of the same species have a steroid-like structure [7-9], the structure does resemble that of marine furanosesterterpene natural products, such as variabilin [10,11], which exhibit a large spectrum of intriguing biological activities $[12,13]$. Therefore, compound 1 is also expected to possess biological activities similar to those of other furanosesterterpenes.

In addition, medium-sized lactones (8-11 membered rings) are significant structural motifs because they are found in many

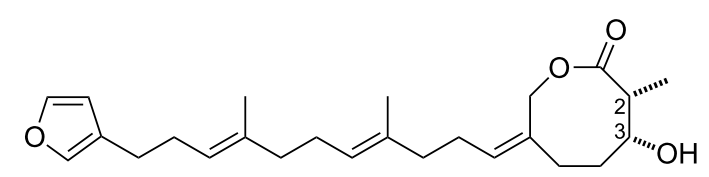

Figure 1: Proposed structure of astakolactin (1).

natural products possessing useful biological activities [14-19]. Among them, the 8-membered (and 9-membered) lactone framework is rather unusual in nature [20-24]. We have already developed the synthetic method of lactones with various ring sizes using 2-methyl-6-nitrobenzoic anhydride (MNBA) under mild reaction conditions in the presence of a nucleophilic catalyst such as 4-(dimethylamino)pyridine (DMAP) [25,26]. By using this method, we have demonstrated that unusual saturated medium-sized lactones, which are generally difficult to construct because of the ring strain and transannular interac- 
tions $[27,28]$, can be effectively prepared [29,30]. Therefore, in order to determine the chemical structure and the expected biological activity of compound $\mathbf{1}$, we executed the total synthesis of compound 1 by exploitng the MNBA-mediated lactonization for the formation of its 8-membered lactone moiety.

\section{Results and Discussion}

The rationalized synthesis of $\mathbf{1}$ primarily involved the linear synthesis of the prenyl chain precursor from commercially available $(E, E)$-farnesol to form the corresponding seco-acid and the subsequent construction of the 8 -membered lactone moiety. The retrosynthetic analysis of $\mathbf{1}$ is depicted in Scheme 1 [31].

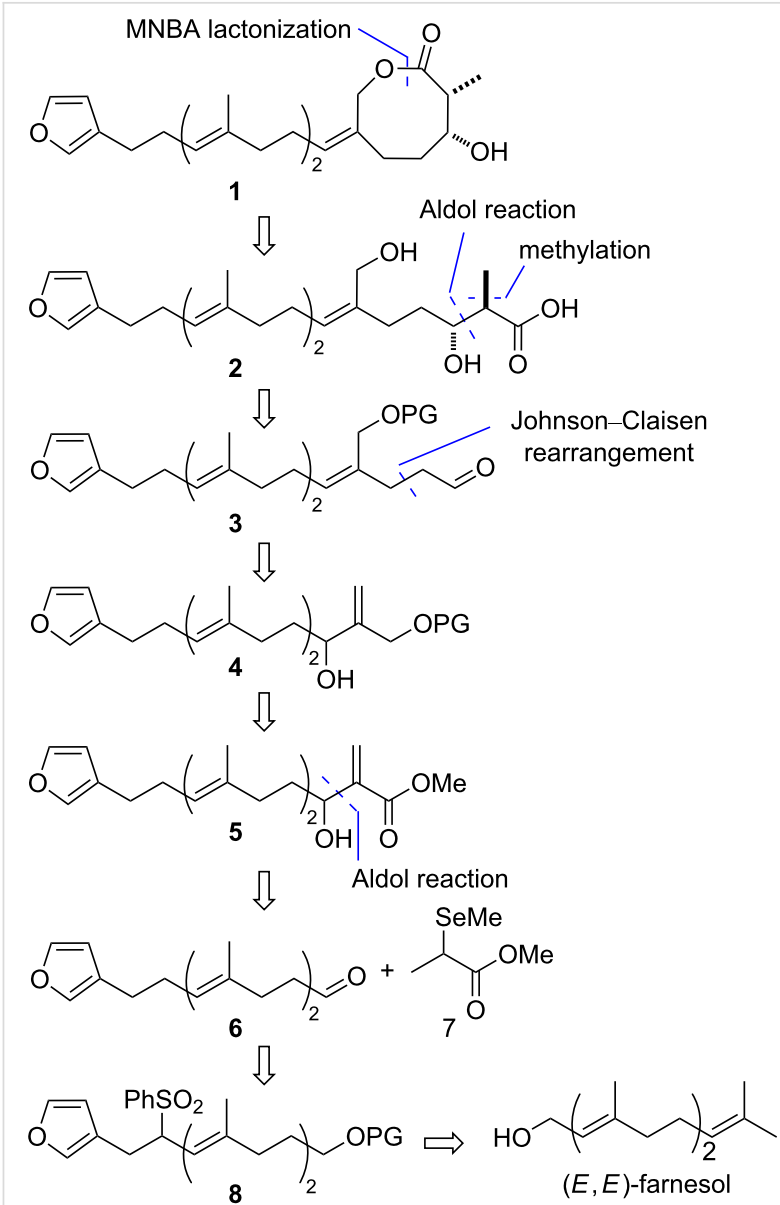

Scheme 1: Retrosynthetic analysis.

First, the 8-membered ring in $\mathbf{1}$ could be efficiently constructed via lactonization using MNBA with DMAP. The chain precursor 2 would be constructed via an aldol reaction with ethyl acetate, followed by anti-selective methylation [32,33]. The trisubstituted alkene moiety of the prenyl chain of $\mathbf{3}$ could be stereoselectively constructed via a Johnson orthoester-Claisen rearrangement of 4 [34-36], which would be generated from compound $\mathbf{5}$. The construction of the $\alpha$-methylene- $\beta$ hydroxy ester moiety in $\mathbf{5}$, which is commonly known as a Morita-Baylis-Hillman adduct, would be achieved via an aldol reaction between aldehyde 6 and ester 7 , followed by oxidative deselenization [37]. The linear precursor 8 would be prepared from $(E, E)$-farnesol using the previously reported method based on the Julia-Kocienski-type transformation [11].

The synthetic route to $\mathbf{1}$ is depicted in Scheme 2. It commenced from the readily accessible furanylated alcohol 13 [11], which was prepared from $(E, E)$-farnesol via a 10 -step sequence. First, oxidation of $\mathbf{1 3}$ provided aldehyde $\mathbf{6}$. The aldol reaction of $\mathbf{6}$ with ester 7 in the presence of base and the subsequent oxidative deselenization of the resulting adduct $\mathbf{1 4}$ yielded a Morita-Baylis-Hillman-type product 5 [37] in two steps. Reduction of $\mathbf{5}$ and the regioselective protection of the lesshindered primary hydroxy group in the resulting diol $\mathbf{1 5}$ gave the monoprotected alcohol 16. This alcohol was then subjected to the Johnson orthoester-Claisen rearrangement, yielding only the $(Z)$-isomer 17 [36] in satisfactory yield. After the reduction of $\mathbf{1 7}$, the resulting aldehyde $\mathbf{1 8}$ was subjected to the aldol reaction with ethyl acetate to afford the adduct 19. Diastereoselective methylation of the ester enolate moiety of 19 with MeI afforded only the anti-product $\mathbf{2 0}[32,33]$, which was then subjected to the deprotection of the TBDPS group with HF-pyridine, followed by cleavage of the ethyl ester group in $\mathbf{2 1}$ to give the desired seco-acid $\mathbf{2}$ in high yield.

Eventually, the lactonization of $\mathbf{2}$ was performed under several sets of reaction conditions (Scheme 3 and Table 1). We preliminarily attempted the Yamaguchi mixed-anhydride method [38] with 2,4,6-trichlorobenzoyl chloride (TCBC) as an activating agent, which is one of the best-known lactonization methods so far. However, the desired lactone $\mathbf{1}$ was obtained in a lower yield (33\%, Table 1, entry 1$)$ accompanied by unidentified complex products. Moreover, the $S$-pyridyl ester lactonization method [39] afforded no desired product at all as shown in Table 1, entry 2. Next, the MNBA-mediated lactonization $[25,26,29,30]$ was then carried out; in sharp contrast to the first two methods, only the targeted 8 -membered lactone 1 was selectively obtained in moderate yield (60\%, Table 1 , entry 3$)$, and formation of the undesired $\beta$-lactone was avoided. Furthermore, the lactonization yield was improved from 60 to $71 \%$ by decreasing the substrate concentration from 2.0 to $1.0 \mathrm{mM}$ (Table 1, entry 4). During the MNBA-mediated lactonization, no epimerization occurred at the $\alpha$ position of lactone carbonyl group. Thus, the total synthesis of the proposed structure of $\mathbf{1}$ was achieved.

We next focused on the synthesis of the diastereomer of $1,2,3-$ trans-astakolactin (1'), to thoroughly uncover its molecular 

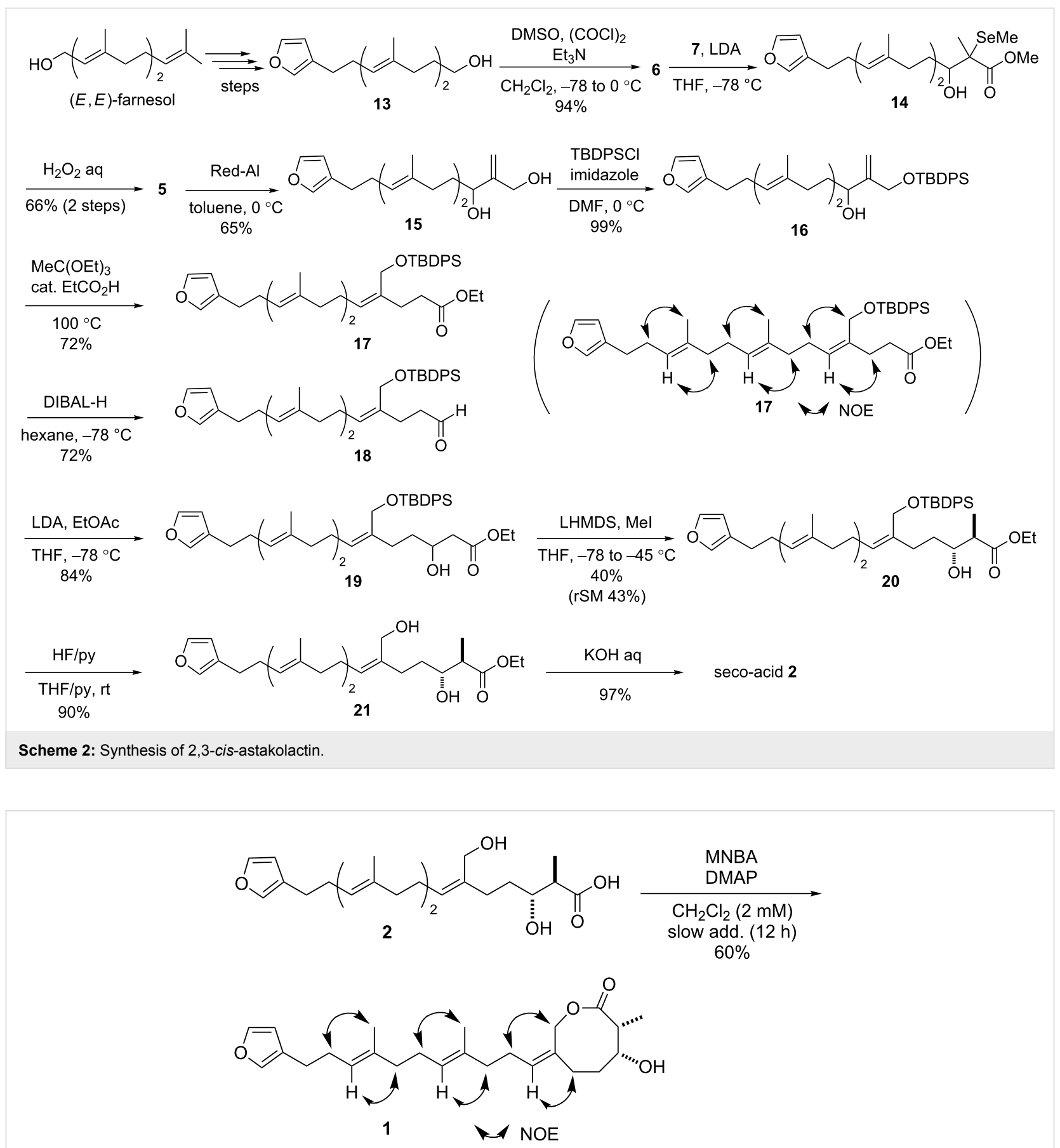

Scheme 3: MNBA-mediated lactonization.

structure and stereochemistry, starting from the aldehyde 18, The asymmetric Mukaiyama aldol reaction of aldehyde $\mathbf{1 8}$ with which was prepared according to the procedure [11] described enol silyl ether 22 (derived from $S$-ethyl propanethioate) in the in Scheme 2. It was postulated that the precursor 26 (Scheme 4) of the ring-closed product (1') possessing a syn- $\alpha$-methyl- $\beta$ hydroxy carboxylic acid moiety could be accessed via an asymmetric Mukaiyama aldol reaction [40-42] and our universal lactonization strategy. The synthetic route to $\mathbf{1}$ ' is shown in Scheme 4. presence of $(S)$-diamine-Sn(II) complex $(S)$-23 as the catalyst and $n-\mathrm{Bu}_{2} \mathrm{Sn}(\mathrm{OAc})_{2}$ proceeded smoothly to afford the corresponding aldol 24 as the desired (2,3)-syn adduct in good yield and excellent enantio- and diastereoselectivities $(90 \%$ yield, $83 \%$ ee for $s y n$, and 93/7 syn/anti ratio). Next, the transformation to the seco-acid $\mathbf{2 6}$ was achieved via successive deprotec- 
Table 1: Yields of astakolactin (1) using several lactonizations.

\begin{tabular}{|c|c|c|c|}
\hline Entry & Reagents (equiv) & Conditions & Yield $/ \%^{a}$ \\
\hline 1 & TCBC (1.0)/Et $3 \mathrm{~N}(1.1) / \mathrm{DMAP}(6.0)$ & $\begin{array}{c}\mathrm{THF} / \mathrm{CH}_{2} \mathrm{Cl}_{2}(2 \mathrm{mM}) \\
\text { slow add. }(12 \mathrm{~h})\end{array}$ & 33 \\
\hline 2 & $(\mathrm{PyS})_{2}(1.5) / \mathrm{PPh}_{3}(1.6) / \mathrm{Ag}(\mathrm{OTf})(2.0)$ & $\begin{array}{l}\mathrm{CHCl}_{3} / \mathrm{MeCN}(2 \mathrm{mM}) \\
\quad \text { slow add. }(12 \mathrm{~h})\end{array}$ & N.D. \\
\hline 3 & MNBA (1.3)/DMAP (6.0) & $\begin{array}{l}\mathrm{CH}_{2} \mathrm{Cl}_{2}(2 \mathrm{mM}) \\
\text { slow add. }(12 \mathrm{~h})\end{array}$ & 60 \\
\hline 4 & MNBA (1.3)/DMAP (6.0) & $\begin{array}{l}\mathrm{CH}_{2} \mathrm{Cl}_{2}(1 \mathrm{mM}) \\
\text { slow add. }(12 \mathrm{~h})\end{array}$ & 71 \\
\hline
\end{tabular}

alsolated yield

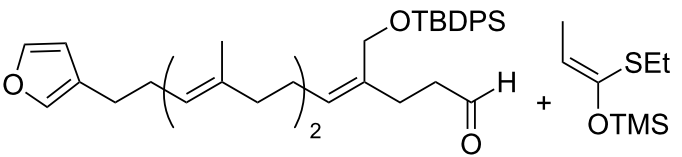

18<smiles>CCSC(=O)[C@H](S)[C@@H](O)CC/C(=C/C(C)C)C[OH+]C/C(C)=C/C(C)(C)Cc1ccoc1</smiles>

24<smiles>CCSC(=O)[C@H](C)[C@@H](O)CC/C(=C\C(C)(C)CC/C(C)=C/C(C)(C)Cc1ccoc1)CO</smiles>

25<smiles>CC(CC/C(C)=C/C(C)=C(/C)Cc1ccoc1)=C(CO)CC[C@@H](O)[C@@H](C)C(=O)O</smiles>

26

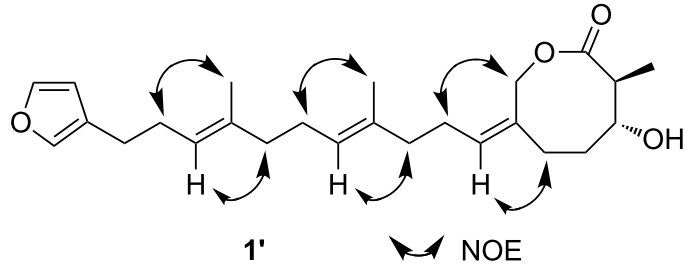

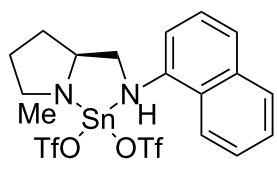

(S)-23

$n-\mathrm{Bu}_{2} \mathrm{Sn}(\mathrm{OAc})_{2}$

$\mathrm{CH}_{2} \mathrm{Cl}_{2},-78^{\circ} \mathrm{C}$

$90 \%, 83 \%$ ee

syn $/$ anti $=93 / 7$

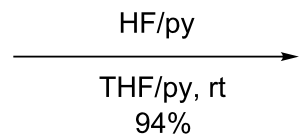

$\underset{\substack{\mathrm{THF} / \mathrm{H}_{2} \mathrm{O}, 0^{\circ} \mathrm{C} \\ 87 \%}}{\stackrel{\mathrm{H}_{2} \mathrm{O}_{2} \text { aq }}{\longrightarrow}}$

MNBA

DMAP

$\mathrm{CH}_{2} \mathrm{Cl}_{2}(2 \mathrm{mM})$

slow add. (12 h)

$62 \%$

Scheme 4: Synthesis of 2,3-trans-astakolactin.

tion of the TBDPS group and the thioester moiety in $\mathbf{2 5}$. The lactonization of $\mathbf{2 6}$ was then performed in the presence of MNBA and DMAP to afford 1' with the desired stereochemistry in $62 \%$ yield.
Finally, determination of the exact structure of astakolactin was attempted by comparing the ${ }^{1} \mathrm{H}$ and ${ }^{13} \mathrm{C}$ NMR spectra of the synthetic compounds $\mathbf{1}$ and $\mathbf{1}$ ' with those reported for astakolactin (Figure 2 and Figure 3). 


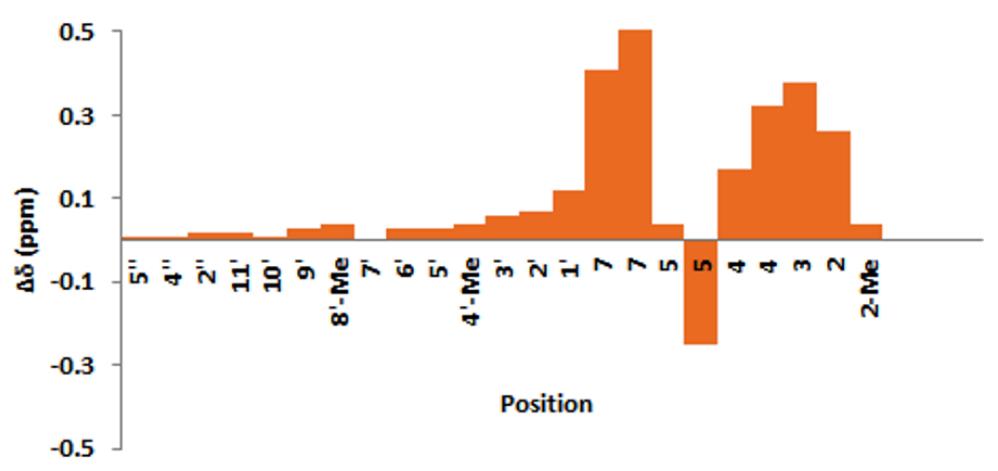

Figure 2: $\Delta \delta(\mathrm{ppm})$ of ${ }^{1} \mathrm{H}$ NMR chemical shifts in $1 . \Delta \delta$ corresponds to the difference in chemical shift for natural and synthetic products $(\Delta \delta=\delta($ synthetic) $-\delta$ (natural)).

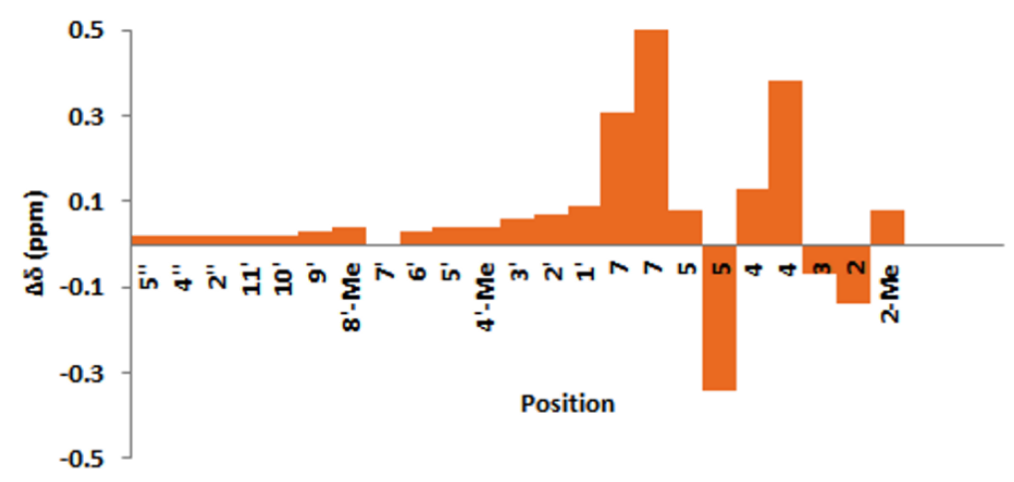

Figure 3: $\Delta \delta(\mathrm{ppm})$ of ${ }^{1} \mathrm{H}$ NMR chemical shifts in $\mathbf{1}^{1} . \Delta \delta$ corresponds to the difference in chemical shift for natural and synthetic products $(\Delta \delta=\delta($ synthetic) $-\delta$ (natural)).

The chemical shifts for the terpene chain of the synthetic compound $\mathbf{1}$ in the ${ }^{1} \mathrm{H}$ and ${ }^{13} \mathrm{C}$ NMR spectra were quite similar to those in the spectra of the natural product (Figure 2; see also Supporting Information File 1). However, the chemical shifts corresponding to the lactone ring moiety (from $\mathrm{C}-1$ to $\mathrm{C}-7$ ) in the ${ }^{1} \mathrm{H}$ and ${ }^{13} \mathrm{C}$ NMR spectra were somewhat different from those in the corresponding spectra of the natural product. Similar discrepancies in the spectral data were also found for the diastereomer 1' (Figure 3; see also Supporting Information File 1). These facts indicate that the proposed eight-membered lactone moiety is not comprised in the naturally occurring astakolactin. On the basis of these results, it was concluded that the structures of synthetic compounds $\mathbf{1}$ and $\mathbf{1}$ ' and the natural product are very similar, but not completely identical.

\section{Conclusion}

In conclusion, we have achieved the total synthesis of the proposed structures of astakolactin (1) and its stereoisomer (1'), with a Johnson-Claisen rearrangement, an asymmetric
Mukaiyama aldol reaction, and our MNBA-mediated lactonization as key steps. It was found that the ${ }^{1} \mathrm{H}$ and ${ }^{13} \mathrm{C}$ NMR data of synthesized $\mathbf{1}$ and 1' are not identical with those of the natural compound. Further studies to elucidate the complete structure of astakolactin are now in progress.

\section{Experimental}

General procedure for the synthesis of 1 using the MNBAmediated lactonization. To a solution of MNBA (14 mg, $0.04 \mathrm{~mol}$ ) and DMAP (23 mg, $0.19 \mathrm{mmol})$ in dichloromethane $(25 \mathrm{~mL})$ at room temperature was slowly added a solution of the seco-acid $2(13 \mathrm{mg}, 0.03 \mathrm{~mol})$ in dichloromethane $(6.2 \mathrm{~mL})$ with a mechanically driven syringe over a $12 \mathrm{~h}$ period. After cooling to $0{ }^{\circ} \mathrm{C}$, saturated aqueous sodium hydrogen carbonate was added. The mixture was extracted with dichloromethane, and the organic layer was washed with brine and water and dried over sodium sulfate. After evaporation of the solvent, the crude product was purified by thin-layer chromatography on silica gel (hexane/ethyl acetate 2:1) to afford $\mathbf{1}$ ( $9 \mathrm{mg}, 71 \%$ ). IR 
(neat): $3455,2931,1735 \mathrm{~cm}^{-1} ;{ }^{1} \mathrm{H} \mathrm{NMR}\left(\mathrm{CDCl}_{3}\right) \delta 7.33(\mathrm{~s}, 1 \mathrm{H}$, 5'-H), 7.21 (s, 1H, 2''-H), 6.27 (s, 1H, 4''-H), 5.33 (t, $J=7.5$ $\left.\mathrm{Hz}, 1 \mathrm{H}, 1^{\prime}-\mathrm{H}\right), 5.17$ (t, $\left.J=7.5 \mathrm{~Hz}, 1 \mathrm{H}, 9^{\prime}-\mathrm{H}\right), 5.10$ (t, $J=7.5$ $\mathrm{Hz}, 1 \mathrm{H}, 5$ '-H), 5.08 (d, $J=12.0 \mathrm{~Hz}, 1 \mathrm{H}, 7-\mathrm{H}), 4.60$ (d, $J=12.0$ $\mathrm{Hz}, 1 \mathrm{H}, 7-\mathrm{H}), 4.09-4.02(\mathrm{~m}, 1 \mathrm{H}, 3-\mathrm{H}), 2.96$ (dq, $J=5.0,7.0 \mathrm{~Hz}$, $1 \mathrm{H}, 2-\mathrm{H}), 2.45\left(\mathrm{t}, J=7.0 \mathrm{~Hz}, 2 \mathrm{H}, 11^{\prime}-\mathrm{H}\right), 2.30$ (ddd, $J=2.5$, $8.5,14.5 \mathrm{~Hz}, 1 \mathrm{H}, 5-\mathrm{H}), 2.24\left(\mathrm{dt}, J=7.0,7.5 \mathrm{~Hz}, 2 \mathrm{H}, 10^{\prime}-\mathrm{H}\right)$, 2.12 (dt, $\left.J=7.5,7.5 \mathrm{~Hz}, 2 \mathrm{H}, 2^{\prime}-\mathrm{H}\right), 2.08$ (dt, $J=7.5,7.5 \mathrm{~Hz}$, $\left.2 \mathrm{H}, 6{ }^{\prime}-\mathrm{H}\right), 2.01$ (dd, $\left.J=7.5,14.5 \mathrm{~Hz}, 1 \mathrm{H}, 5-\mathrm{H}\right), 2.01$ (t, $J=7.5$ Hz, 2H, 3'-H), 1.99 (t, J= 7.5 Hz, 2H, 7'-H), 1.94-1.85 (m, 1H, $4-\mathrm{H}), 1.83(\mathrm{~d}, J=7.0 \mathrm{~Hz}, 1 \mathrm{H}, \mathrm{OH}), 1.83-1.76(\mathrm{~m}, 1 \mathrm{H}, 4-\mathrm{H})$, 1.59 (s, 6H, 4'-Me, 8'-Me), 1.22 (d, $J=7.0 \mathrm{~Hz}, 3 \mathrm{H}, 2-\mathrm{Me})$; ${ }^{13} \mathrm{C} \mathrm{NMR}\left(\mathrm{CDCl}_{3}\right) \delta 176.6(1), 142.5\left(5^{\prime \prime}\right), 138.8(2$ ') $), 136.2$ (6), 135.7 (8'), 134.1 (4'), 130.5 (1'), 125.0 (3'), 124.9 (5'), 123.8 (9'), 111.1 (4'’), 74.1 (3), 65.7 (7), 42.5 (2), 39.6 (7'), 39.4 (3'), 35.1 (4), 29.9 (5), 28.4 (10'), 26.6 (6'), 26.2 (2'), 25.0 (11'), 16.0 (4'-Me, 8'-Me), 11.6 (2-Me); HRMS: [M + Na $]^{+}$ calcd for $\mathrm{C}_{25} \mathrm{H}_{36} \mathrm{O}_{4} \mathrm{Na}, 423.2506$; found, 423.2488.

\section{Supporting Information}

\section{Supporting Information File 1}

Experimental procedures, analyitical data, and copies of ${ }^{1} \mathrm{H}$ and ${ }^{13} \mathrm{C}$ NMR spectra of all new compounds.

[http://www.beilstein-journals.org/bjoc/content/ supplementary/1860-5397-10-252-S1.pdf]

\section{Acknowledgements}

The authors are grateful to Professor Vassilios Roussis (University of Athens) for giving the spectral data of astakolactin. This study was partly supported by a Research Grant from the Center for Chirality and Grants-in-Aid for Scientific Research from the Ministry of Education, Science, Sports and Culture, Japan.

\section{References}

1. Hanson, J. R. Nat. Prod. Rep. 1986, 3, 123-132. doi:10.1039/np9860300123

2. Hanson, J. R. Nat. Prod. Rep. 1992, 9, 481-489. doi:10.1039/np9920900481

3. Hanson, J. R. Nat. Prod. Rep. 1996, 13, 529-535. doi:10.1039/np9961300529

4. Faulkner, D. J. Nat. Prod. Rep. 2002, 19, 1-49. doi:10.1039/b009029h

5. Liu, Y.; Wang, L.; Jung, J. H.; Zhang, S. Nat. Prod. Rep. 2007, 24 , 1401-1429. doi:10.1039/b617259h

6. Tsoukatou, M.; Siapi, H.; Vagias, C.; Roussis, V. J. Nat. Prod. 2003, 66, 444-446. doi:10.1021/np020471u

7. Cimino, G.; De Rosa, S.; De Stefano, S.; Sodano, G. Comp. Biochem. Physiol., Part B: Comp. Biochem. 1982, 73b, 471-474. doi:10.1016/0305-0491(82)90061-x

8. Cafieri, F.; De Napoli, L.; Fattorusso, E.; Santacroce, C.; Sica, D. Tetrahedron Lett. 1977, 18, 477-480. doi:10.1016/S0040-4039(01)92670-x
9. Cimino, G.; Cafieri, F.; De Napoli, L.; Fattorusso, E. Tetrahedron Lett 1978, 19, 2041-2044. doi:10.1016/S0040-4039(01)94744-6

10. Faulkner, D. J. Tetrahedron Lett. 1973, 14, 3821-3822. doi:10.1016/S0040-4039(01)87045-3

11. Takabe, K.; Hashimoto, H.; Sugimoto, H.; Nomoto, M.; Yoda, H. Tetrahedron: Asymmetry 2004, 15, 909-912. doi:10.1016/j.tetasy.2004.01.031

12. Barrow, C. J.; Blunt, J. W.; Munro, M. H. G. J. Nat. Prod. 1989, 52, 346-359. doi:10.1021/np50062a022

13. Liu, Y.; Mansoor, T. A.; Hong, J.; Lee, C.-O.; Sim, C. J.; Im, K. S.; Kim, N. D.; Jung, J. H. J. Nat. Prod. 2003, 66, 1451-1456. doi:10.1021/np030268e

14. Nicolaou, K. C. Tetrahedron 1977, 33, 683-710. doi:10.1016/0040-4020(77)80180-4

15. Masamune, S.; Bates, G. S.; Corcoran, J. W. Angew. Chem., Int. Ed. Engl. 1977, 16, 585-607. doi:10.1002/anie.197705851

16. Paterson, I.; Mansuri, M. M. Tetrahedron 1985, 41, 3569-3624. doi:10.1016/S0040-4020(01)91380-8

17. Rousseau, G. Tetrahedron 1995, 51, 2777-2849. doi:10.1016/0040-4020(94)01064-7

18. Norcross, R. D.; Paterson, I. Chem. Rev. 1995, 95, 2041-2114. doi:10.1021/cr00038a012

19. Parenty, A.; Moreau, X.; Campagne, J.-M. Chem. Rev. 2006, 106, 911-939. doi:10.1021/cr0301402

20. Tapiolas, D. M.; Roman, M.; Fenical, W.; Stout, T. J.; Clardy, J. J. Am. Chem. Soc. 1991, 113, 4682-4683. doi:10.1021/ja00012a048

21. Buszek, K. R.; Sato, N.; Jeong, Y. J. Am. Chem. Soc. 1994, 116, 5511-5512. doi:10.1021/ja00091a082

22. McWilliams, J. C.; Clardy, J. J. Am. Chem. Soc. 1994, 116, 8378-8379. doi:10.1021/ja00097a060

23. Buszek, K. R.; Sato, N.; Jeong, Y. Tetrahedron Lett. 2002, 43, 181-184. doi:10.1016/S0040-4039(01)02078-0

24. O'Sullivan, P. T.; Buhr, W.; Fuhry, M. A. M.; Harrison, J. R.; Davies, J. E.; Feeder, N.; Marshall, D. R.; Burton, J. W.; Holmes, A. B. J. Am. Chem. Soc. 2004, 126, 2194-2207. doi:10.1021/ja038353w

25. Shiina, I.; Kubota, M.; Oshiumi, H.; Hashizume, M. J. Org. Chem. 2004, 69, 1822-1830. doi:10.1021/jo030367x

26. Shiina, I. Bull. Chem. Soc. Jpn. 2014, 87, 196-233. doi:10.1246/bcsj.20130216

27. Illuminati, G.; Mandolini, L. Acc. Chem. Res. 1981, 14, 95-102. doi:10.1021/ar00064a001

28. Galli, C.; Mandolini, L. Eur. J. Org. Chem. 2000, 3117-3125. doi:10.1002/1099-0690(200009)2000:18<3117::AID-EJOC3117>3.0.C 0;2-5

29. Shiina, I.; Hashizume, M.; Yamai, Y.; Oshiumi, H.; Shimazaki, T.; Takasuna, Y.; Ibuka, R. Chem. - Eur. J. 2005, 11, 6601-6608. doi:10.1002/chem.200500417

30. Shiina, I. Chem. Rev. 2007, 107, 239-273. doi:10.1021/cr050045o

31. Shibamoto, K.; Fukui, H.; Shiina, I. Abstracts of Papers, 49th Symposium on the Chemistry of Natural Products, Sapporo, 2007, 49, 569-574.

http://ci.nii.ac.jp/lognavi?name=nels\&lang=en\&type=pdf\&id=ART00087 07858

32. Seebach, D.; Wasmuth, D. Helv. Chim. Acta 1980, 63, 197-200. doi:10.1002/hlca.19800630118

33. Seebach, D.; Aebi, J.; Wasmuth, D. Org. Synth. 1985, 63, 109.

34. Johnson, W. S.; Werthemann, L.; Bartlett, W. R.; Brocksom, T. J.; Li, T.-T.; Faulkner, D. J.; Petersen, M. R. J. Am. Chem. Soc. 1970, 92, 741-743. doi:10.1021/ja00706a074 
35. Castro, A. M. M. Chem. Rev. 2004, 104, 2939-3002. doi:10.1021/cr020703u

36. Trost, B. M.; Machacek, M. R.; Tsui, H. C. J. Am. Chem. Soc. 2005, 127, 7014-7024. doi:10.1021/ja050340q

37. Shiina, I.; Yamai, Y.; Shimazaki, T. J. Org. Chem. 2005, 70, 8103-8106. doi:10.1021/jo051276y

38. Inanaga, J.; Hirata, K.; Saeki, H.; Katsuki, T.; Yamaguchi, M. Bull. Chem. Soc. Jpn. 1979, 52, 1989-1993. doi:10.1246/bcsj.52.1989 39. Corey, E. J.; Nicolaou, K. C. J. Am. Chem. Soc. 1974, 96, 5614-5616. doi:10.1021/ja00824a073

40. Mukaiyama, T.; Kobayashi, S.; Uchiro, H.; Shiina, I. Chem. Lett. 1990, 19, 129-132. doi:10.1246/cl.1990.129

41. Kobayashi, S.; Uchiro, H.; Fujishita, Y.; Shiina, I.; Mukaiyama, T. J. Am. Chem. Soc. 1991, 113, 4247-4252. doi:10.1021/ja00011a030 42. Shiina, I. Chem. Rec. 2014, 14, 144-183. doi:10.1002/tcr.201300022

\section{License and Terms}

This is an Open Access article under the terms of the Creative Commons Attribution License

(http://creativecommons.org/licenses/by/2.0), which permits unrestricted use, distribution, and reproduction in any medium, provided the original work is properly cited.

The license is subject to the Beilstein Journal of Organic Chemistry terms and conditions:

(http://www.beilstein-journals.org/bjoc)

The definitive version of this article is the electronic one which can be found at: $\underline{\text { doi: } 10.3762 / \text { bjoc. } 10.252}$ 